\title{
Non linear Optimum Interacting Multiple Model Smoother for GPS Navigation System
}

\author{
H. Ramesh \\ M.E., Applied Electronics, Final year, Dept of ECE, University Dept Tirunelveli, Anna university, Chennai
}

\begin{abstract}
The navigation problem is to direct the movement of vehicle so as to arrive at a given destination.The single model unscented filter gives better accuracy for non-linear navigation problems using unscented transform.But it fails to address noise variations in vehicle dynamics. Hence the multiple model filtering[3] is required to deal with both non-linearity and noise variations in vehicle movement.The interacting multiple model unscented filter(IMMUF) gives better navigation results compared to individual model filters like EKF ,UKF and IMM-EKF.In this paper, the Interacting multiple model unscented smoothing approach (IMMUS) which combines the estimates of two separately running forward and back ward IMMUF is introduced to improve navigation results.The simulation result proves that IMMUS approach provides better estimation accuracy compared to IMMUF and single model UKF.

Keywords- GPS; INS; Interacting Multiple Model (IMM);Extended Kalman Filter(EKF); Unscented Kalman Filter (UKF); Unscented Two Filter Smoother(UTFS); Interacting Multiple Model Unscented Filter(IMMUF);Interacting Multiple Model Unscented Smoother(IMMUS)
\end{abstract}

\section{INTRODUCTION}

An important part of navigation is determining one's location relative to one's destination and relative to local features related to travel (roads, shipping lanes, airways).The solution to navigation problem generally requires observations or measurements of some kind and ability to use that information to determine one's location relative to the destination. A unscented Kalman filter[10,11] combines all available measurement data, plus prior knowledge about the system and measuring devices, to produce an estimate of the desired variables in nonlinear navigation problems. But its estimate is not satisfactory during noise variations in vehicle noise. An interacting multiple model filter approach is introduced to deal with noise uncertainty and system non linearity simultaneously. Using multiple model filter approach, one can achieve the better estimates of the vehicle states at a given time based on all measurements up to the current estimation time. The best estimate at the given time can be improved significantly by smoothing [1,2], which uses more measurements beyond the current estimation time.

The proposed IMMUS approach employs two IMMUFs running forward and backward in time and fixed interval smoothing algorithm[3,4](UTFS) which combines the estimates of two filters.Since more measurements are used to estimate the vehicles position at current estimation time ,the IMMUS approach gives better result than IMMUF.

\section{ESTIMATION METHODS}

Several vehicle state estimation algorithms like EKF,UKF,IMM-EKF [9,10,11]and IMMUF are available to address the nonlinear navigation problems. In this paper the advantages of multiple model smoothing(IMMUS) approach over UKF and IMMUF is described.

A.UNSCENTED KALMAN FILTER

In EKF the state distribution is propagated analytically through the first-order linearization of the nonlinear system due to which, the posterior mean and covariance could be corrupted. The UKF, which is a derivative-free alternative to EKF, overcomes this problem by using a deterministic sampling approach.The state distribution is represented using a minimal set of carefully chosen sample points, called sigma points. Like EKF, UKF consists of the same two steps: model forecast and data assimilation, except they are preceded now by another step for the selection of sigma points.The UKF is founded on the intuition that it is easier to approximate a probability distribution than it is to approximate an arbitrary nonlinear function or transformation. The sigma points are chosen so that their mean and covariance to be exactly xk-1 and Pk-1. Each sigma point is then propagated through the nonlinear functions yielding in the end a cloud of transformed points. The new estimated mean and covariance are then computed based on their statistics. This process is called unscented transformation. The figure.1. explains the flow of UKF algorithm.

The $n$-dimensional random variable with mean $\bar{x}$ and covariance $P_{x x}$ is approximated by $2 n+1$ weighted point by

$$
\begin{aligned}
& \chi_{0}=\overline{\mathbf{x}} \\
& \chi_{i}=\overline{\mathbf{x}}+\left(\sqrt{(\mathbf{n}+\mathbf{k}) \mathbf{p}_{x x}}\right)_{i} \\
& \chi_{i}=\overline{\mathbf{x}}-\left(\sqrt{(\mathbf{n}+\mathbf{k}) \mathbf{p}_{x x}}\right)_{i}
\end{aligned}
$$




$$
\begin{aligned}
& \mathrm{w}_{\mathrm{o}}=\mathrm{k} /(\mathrm{n}+\mathrm{k}) \\
& \mathrm{w}_{\mathrm{i}}=1 / 2(\mathrm{n}+\mathrm{k}) \\
& \mathrm{w}_{\mathrm{i}+\mathrm{n}}=1 / 2(\mathrm{n}+\mathrm{k})
\end{aligned}
$$

Where $\chi$ :Sigma point, w: Weight, k: constant.

The sigma points are passed through the non-linear function to yield the set of transformed sigma points.

$$
\varsigma_{i}=f\left(\chi_{i}\right)
$$

The mean and covariance are given by the weighted average and the weighted outer product of the transformed points

$$
\begin{aligned}
& \overline{\mathrm{y}}=\sum_{i=0}^{2 n} \mathrm{w}_{\mathrm{i}} \varsigma_{i} \\
& \mathrm{p}_{\mathrm{yy}}=\sum_{i=0}^{2 n} \mathrm{w}_{\mathrm{i}}\left\{\varsigma_{\mathrm{i}}-\overline{\mathrm{y}}\right\}\left\{\varsigma_{\mathrm{i}}-\overline{\mathrm{y}}\right\}^{\mathrm{T}}
\end{aligned}
$$

The time prediction and measurement update is done using this mean and covariance .

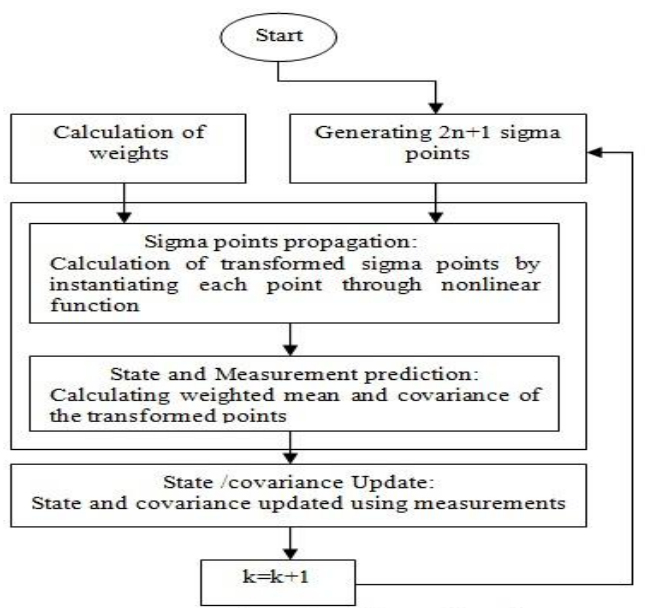

Figure .1 Flow Chart of UKF algorithm

\section{B.InTERACting MultiPle Model Unscented Filter}

The block diagram of the IMMUF algorithm is shown in Fig.2. The IMMUF algorithm uses Markovian model probabilities to weight the input and output of the bank of parallel UKFs at each time instant. The overall estimate is obtained by a combination of the estimates from the filters running in parallel based on the individual models that match the vehicle behaviour. The IMM cycle consists of four major stages: interaction (mixing), filtering, model probability calculation, and estimate combination as described in the following subsections $[7,8,9]$.

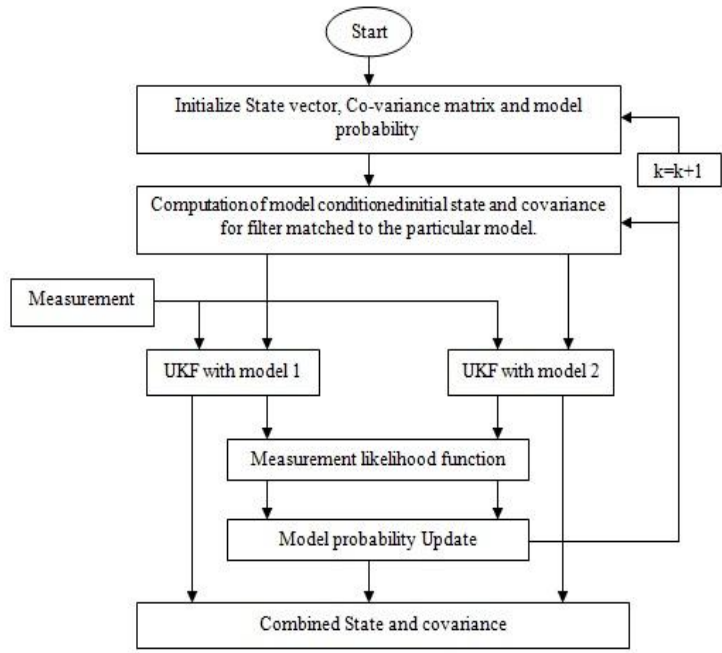

Figure 2 Flow Chart of IMMUF algorithm 


\section{C.INTERACTING MultiPle MOdel UnSCENTED SMOOTHER}

The block diagram of the proposed IMMUS algorithm is shown in Fig.4 . The IMMUS algorithm consists of multiple modeled filters, one running forward in time and another running backward in time and smoothing equations combining estimates of the two filter

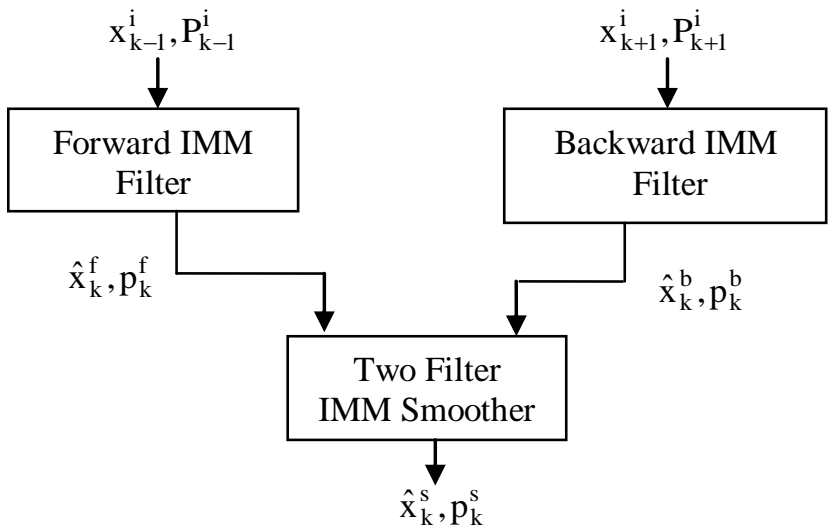

Figure 3. Simplified Block diagram of IMM-smoothing algorithm

The simplified block diagram of the IMM two filter smoothing algorithm is shown in Fig.3. The IMMUS algorithm combines the estimates of two multiple model filters using two filter smoothing algorithm. The IMMUS algorithm uses model probabilities to weight the estimate of the individual filters.

The IMMUS approach combines the estimation of forward IMM unscented filter and backward IMM unscented filter. Let there are two estimates at time $t$, one based on forward filtering up to time $t$ and other being due to backward filtering starting from $t_{f} u p$ to the initial time $t_{0}$. The idea is to obtain a smoothed / improved estimate by fusion of these two estimates $x_{k, f}^{i}$ and $x_{k, b}^{i}$.

The MM smoothed estimate $\hat{x}_{k, s}^{i}$ of $x_{k}^{i}$ is estimated as a linear combination of the two MM filters $\hat{\mathrm{x}}_{\mathrm{k}, \mathrm{f}}^{\mathrm{i}}$ and $\hat{\mathrm{x}}_{\mathrm{k}, \mathrm{b}}^{\mathrm{i}}[5,6]$. Let $\tilde{\mathrm{x}}_{\mathrm{k}, \mathrm{s}}^{\mathrm{i}}$ be the MM smoothed estimate error given by

$$
\tilde{\mathrm{x}}_{\mathrm{k}, s}^{\mathrm{i}}=\hat{\mathrm{x}}_{\mathrm{k}, \mathrm{s}}^{\mathrm{i}}-\mathrm{x}_{\mathrm{k}}^{\mathrm{i}}
$$

The MM smoothed estimate is given by

$$
\hat{\mathrm{x}}_{\mathrm{k}, \mathrm{s}}^{\mathrm{i}}=\mathrm{k}_{1} \hat{\mathrm{x}}_{\mathrm{k}, \mathrm{f}}^{\mathrm{i}}+\mathrm{k}_{2} \cdot \hat{\mathrm{x}}_{\mathrm{k}, \mathrm{b}}^{\mathrm{i}}
$$

From the equation (4) we can write

$$
\mathrm{x}_{\mathrm{k}}^{\mathrm{i}}+\tilde{\mathrm{x}}_{\mathrm{k}, \mathrm{s}}^{\mathrm{i}}=\mathrm{k}_{1}\left(\mathrm{x}_{\mathrm{k}}^{\mathrm{i}}+\tilde{\mathrm{x}}_{\mathrm{k}, \mathrm{f}}^{\mathrm{i}}\right)+\mathrm{k}_{2}\left(\mathrm{x}_{\mathrm{k}}^{\mathrm{i}}+\tilde{\mathrm{x}}_{\mathrm{k}, \mathrm{b}}^{\mathrm{i}}\right)
$$

Where $\tilde{x}_{k, f}^{i}, \tilde{x}_{k, b}^{i}$ are the estimated errors of the MM forward and backward filters.

$$
\tilde{\mathrm{x}}_{\mathrm{k}, \mathrm{s}}^{\mathrm{i}}=\left(\mathrm{k}_{1}+\mathrm{k}_{2}-\mathrm{I}\right) \mathrm{x}_{\mathrm{k}}^{\mathrm{i}}+\mathrm{k}_{1} \tilde{\mathrm{x}}_{\mathrm{k}, \mathrm{f}}^{\mathrm{i}}+\mathrm{k}_{2} \tilde{\mathrm{x}}_{\mathrm{k}, \mathrm{b}}^{\mathrm{i}}
$$

To make our estimate unbiased, $E\left(\tilde{\mathrm{x}}_{\mathrm{k}, \mathrm{s}}^{\mathrm{i}}\right)=0$

$$
\begin{aligned}
& \mathrm{k}_{1}+\mathrm{k}_{2}-\mathrm{I}=0 \\
& \mathrm{k}_{2}=\mathrm{I}-\mathrm{k}_{1}
\end{aligned}
$$

Substituting $\mathrm{k}_{2}$ in the equation 5 , we obtain smoothed estimate.

$$
\hat{\mathrm{x}}_{\mathrm{k}, \mathrm{s}}^{\mathrm{i}}=\mathrm{k}_{1} \cdot \hat{\mathrm{x}}_{\mathrm{k}, \mathrm{f}}^{\mathrm{i}}+\left(\mathrm{I}-\mathrm{k}_{1}\right) \hat{\mathrm{x}}_{\mathrm{k}, \mathrm{b}}^{\mathrm{i}}
$$

Also it can be written as

$$
\hat{\mathrm{x}}_{\mathrm{k}, \mathrm{s}}^{\mathrm{i}}=\hat{\mathrm{x}}_{\mathrm{k}, \mathrm{b}}^{\mathrm{i}}+\mathrm{k}_{1}\left(\hat{\mathrm{x}}_{\mathrm{k}, \mathrm{f}}^{\mathrm{i}}-\hat{\mathrm{x}}_{\mathrm{k}, \mathrm{b}}^{\mathrm{i}}\right)
$$

Next, the covariance matrix of the smoother estimate error is obtained by

$$
\begin{aligned}
& \tilde{\mathrm{x}}_{\mathrm{k}, \mathrm{s}}^{\mathrm{i}}=\mathrm{k}_{1} \tilde{\mathrm{x}}_{\mathrm{k}, \mathrm{f}}^{\mathrm{i}}+\mathrm{k}_{2} \tilde{\mathrm{x}}_{\mathrm{k}, \mathrm{b}}^{\mathrm{i}}=\mathrm{k}_{1} \tilde{\mathrm{x}}_{\mathrm{k}, \mathrm{f}}^{\mathrm{i}}+\left(\mathrm{I}-\mathrm{k}_{1}\right)_{\mathrm{x}}^{\mathrm{i}} \mathrm{i}_{\mathrm{k}, \mathrm{b}} \\
& \mathrm{p}_{\mathrm{k}, \mathrm{s}}^{\mathrm{i}}=\mathrm{k}_{1} \mathrm{p}_{\mathrm{k}, \mathrm{f}}^{\mathrm{i}} \cdot \mathrm{k}_{1}^{\mathrm{T}}+\left(\mathrm{I}-\mathrm{k}_{1}\right) \mathrm{p}_{\mathrm{k}, \mathrm{b}}^{\mathrm{i}}\left(\mathrm{I}-\mathrm{k}_{1}\right)^{\mathrm{T}}
\end{aligned}
$$

By minimizing eqn (13) for gain $\mathrm{K}_{1}$

$$
\begin{aligned}
& 2 \mathrm{k}_{1} \mathrm{p}_{\mathrm{k}, \mathrm{f}}^{\mathrm{i}}-2\left(\mathrm{I}-\mathrm{k}_{1}\right) \mathrm{p}_{\mathrm{k}, \mathrm{b}}^{\mathrm{i}}=0 \\
& \mathrm{k}_{1}=\mathrm{p}_{\mathrm{k}, \mathrm{b}}^{\mathrm{i}}\left(\mathrm{p}_{\mathrm{k}, \mathrm{f}}^{\mathrm{i}}+\mathrm{p}_{\mathrm{k}, \mathrm{b}}^{\mathrm{i}}\right)^{-1}
\end{aligned}
$$




$$
\begin{aligned}
& \mathrm{I}-\mathrm{k}_{1}=\mathrm{I}-\mathrm{p}_{\mathrm{k}, \mathrm{b}}^{\mathrm{i}}\left(\mathrm{p}_{\mathrm{k}, \mathrm{f}}^{\mathrm{i}}+\mathrm{p}_{\mathrm{k}, \mathrm{b}}^{\mathrm{i}}\right)^{-1} \\
& \mathrm{I}-\mathrm{k}_{1}=\mathrm{p}_{\mathrm{k}, \mathrm{f}}^{\mathrm{i}}\left(\mathrm{p}_{\mathrm{k}, \mathrm{f}}^{\mathrm{i}}+\mathrm{p}_{\mathrm{k}, \mathrm{b}}^{\mathrm{i}}\right)^{-1}
\end{aligned}
$$

Substituting eqn (15) and (17) in eqn (13),we will get

$$
\mathrm{p}_{\mathrm{k}, \mathrm{s}}^{\mathrm{i}}{ }^{-1}=\mathrm{p}_{\mathrm{k}, \mathrm{f}}^{\mathrm{i}}{ }^{-1}+\mathrm{p}_{\mathrm{k}, \mathrm{b}}^{\mathrm{i}}{ }^{-1}
$$

Thus, the equation for smoothed covariance of forward and backward IMM filter can be written as

$$
\mathrm{p}_{\mathrm{k}, \mathrm{s}}^{\mathrm{i}}=\left[\mathrm{p}_{\mathrm{k}, \mathrm{f}}^{\mathrm{i}}{ }^{-1}+\mathrm{p}_{\mathrm{k}, \mathrm{b}}^{\mathrm{i}}\right]^{-1}
$$

The eqn (19) proves that the smoothed uncertainity covariance is less than the uncertainity covariance of both forward and backward IMMUF.

The equation for IMM smoothed estimate is obtained by substituting (15) and (17) in eqn (10)

$$
\hat{\mathrm{x}}_{\mathrm{k}, \mathrm{s}}^{\mathrm{i}}=\mathrm{p}_{\mathrm{k}, \mathrm{b}}^{\mathrm{i}}\left(\mathrm{p}_{\mathrm{k}, \mathrm{f}}^{\mathrm{i}}+\mathrm{p}_{\mathrm{k}, \mathrm{b}}^{\mathrm{i}}\right)^{-1} \cdot \hat{\mathrm{x}}_{\mathrm{k}, \mathrm{f}}^{\mathrm{i}}+\mathrm{p}_{\mathrm{k}, \mathrm{f}}^{\mathrm{i}} \cdot\left(\mathrm{p}_{\mathrm{k}, \mathrm{f}}^{\mathrm{i}}+\mathrm{p}_{\mathrm{k}, \mathrm{b}}^{\mathrm{i}}\right)^{-1} \cdot \hat{\mathrm{x}}_{\mathrm{k}, \mathrm{b}}^{\mathrm{i}}
$$

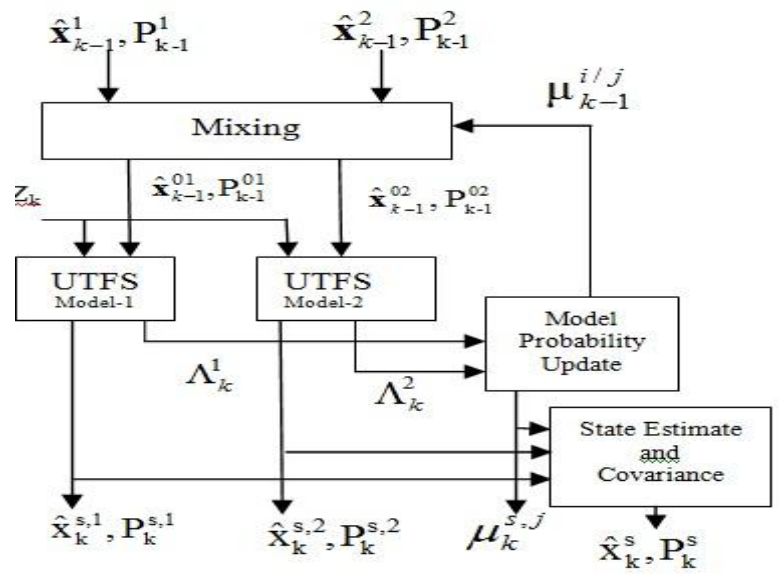

Figure 4. Block diagram of MMUS algorithm Simplifying eqn(20) gives

$$
\hat{\mathrm{x}}_{\mathrm{k}, \mathrm{s}}^{\mathrm{i}}=\frac{\mathrm{p}_{\mathrm{k}, \mathrm{b}}^{\mathrm{i}} \cdot \mathrm{p}_{\mathrm{k}, \mathrm{f}}^{\mathrm{i}}}{\left(\mathrm{p}_{\mathrm{k}, \mathrm{f}}^{\mathrm{i}}+\mathrm{p}_{\mathrm{k}, \mathrm{b}}^{\mathrm{i}}\right)}\left[\left(\mathrm{p}_{\mathrm{k}, \mathrm{f}}^{\mathrm{i}}\right)^{-1} \cdot \hat{\mathrm{x}}_{\mathrm{k}, \mathrm{f}}^{\mathrm{i}}+\left(\mathrm{p}_{\mathrm{k}, \mathrm{b}}^{\mathrm{i}}\right)^{-1} \cdot \hat{\mathrm{x}}_{\mathrm{k}, \mathrm{b}}^{\mathrm{i}}\right]
$$

Thus, the IMM smoothed estimate obtained using the Forward and backward uncertainty covariance is given by

$$
\hat{\mathrm{x}}_{\mathrm{k}, \mathrm{s}}^{\mathrm{i}}=\mathrm{p}_{\mathrm{k}, \mathrm{s}}^{\mathrm{i}}\left[\left(\mathrm{p}_{\mathrm{k}, \mathrm{f}}^{\mathrm{i}}\right)^{-1} \cdot \hat{\mathrm{x}}_{\mathrm{k}, \mathrm{f}}^{\mathrm{i}}+\left(\mathrm{p}_{\mathrm{k}, \mathrm{b}}^{\mathrm{i}}\right)^{-1} \cdot \hat{\mathrm{x}}_{\mathrm{k}, \mathrm{b}}^{\mathrm{i}}\right]
$$

The model conditioned smoothed estimate $x_{k, s}^{j}$ and its uncertainty covariance $P_{k}^{s, j}$ is given by the equation

$$
\begin{aligned}
& \mathrm{x}_{\mathrm{k}, \mathrm{s}}^{\mathrm{j}}=\sum_{\mathrm{i}=1}^{\mathrm{n}} \mu_{\mathrm{k}+1}^{\mathrm{s}, \mathrm{j} / \mathrm{j}} \mathrm{x}_{\mathrm{k}, \mathrm{s}}^{\mathrm{i}} \\
& \mathrm{P}_{\mathrm{k}, \mathrm{s}}^{\mathrm{j}}=\sum_{\mathrm{i}=1}^{\mathrm{n}} \mu_{\mathrm{k}+\mathrm{i}}^{\mathrm{s}, \mathrm{i} / \mathrm{j}}\left[\mathrm{P}_{\mathrm{k}, \mathrm{s}}^{\mathrm{i}}+\left(\mathrm{x}_{\mathrm{k}, \mathrm{s}}^{\mathrm{i}}-\mathrm{x}_{\mathrm{k}, s}^{\mathrm{j}}\right)\left(\mathrm{x}_{\mathrm{k}, \mathrm{s}}^{\mathrm{i}}-\mathrm{x}_{\mathrm{k}, s}^{\mathrm{j}}\right)^{\mathrm{T}}\right]
\end{aligned}
$$

Where

The conditional probability $\mu_{k+1}^{s, i / j}$ is given by

$$
\mu_{k+1}^{s, i / j}=\frac{1}{d_{j}} p_{j i} \Lambda_{k}^{j i}
$$

The term $d_{j}$ is computed by,

$$
d_{j}=\sum_{1}^{n} P_{j i} \Lambda_{k}^{j i}
$$

The likelihood $\Lambda_{k}^{j i}$ is given by 


$$
\begin{aligned}
& \Lambda_{k}^{j i}=N\left(\Delta_{k}^{j i}, D_{k}^{j i}\right) \\
& \text { where } \\
& \Delta_{k}^{j i}=\hat{x}_{k}^{b, i}-x_{k}^{j} \\
& D_{k}^{j i}=\hat{P}_{k}^{b, i}+P_{k}^{j}
\end{aligned}
$$

The overall optimal smoothed estimate and its uncertainty covariance is given by the equation:

$$
\begin{aligned}
& \hat{x}_{k}^{s}=\sum_{i=1}^{n} \mu_{k}^{s, j} x_{k, s}^{j} \\
& P_{k}^{s}=\sum_{i=1}^{n} \mu_{k}^{s, j} \cdot\left[P_{k, s}^{j}+\left(x_{k, s}^{j}-\hat{x}_{k}^{s}\right)\left(x_{k, s}^{j}-\hat{x}_{k}^{s}\right)^{T}\right]
\end{aligned}
$$

Where smoothed model probabilities are computed as

$$
\mu_{k}^{s, j}=\frac{1}{d} d_{j} \mu_{k}^{j}
$$

Where $\mu_{k}^{j}$ is the forward time filtered model probability

d- the normalization constant given by

$$
d=\sum_{j=1}^{n} d_{j} \mu_{k}^{j}
$$

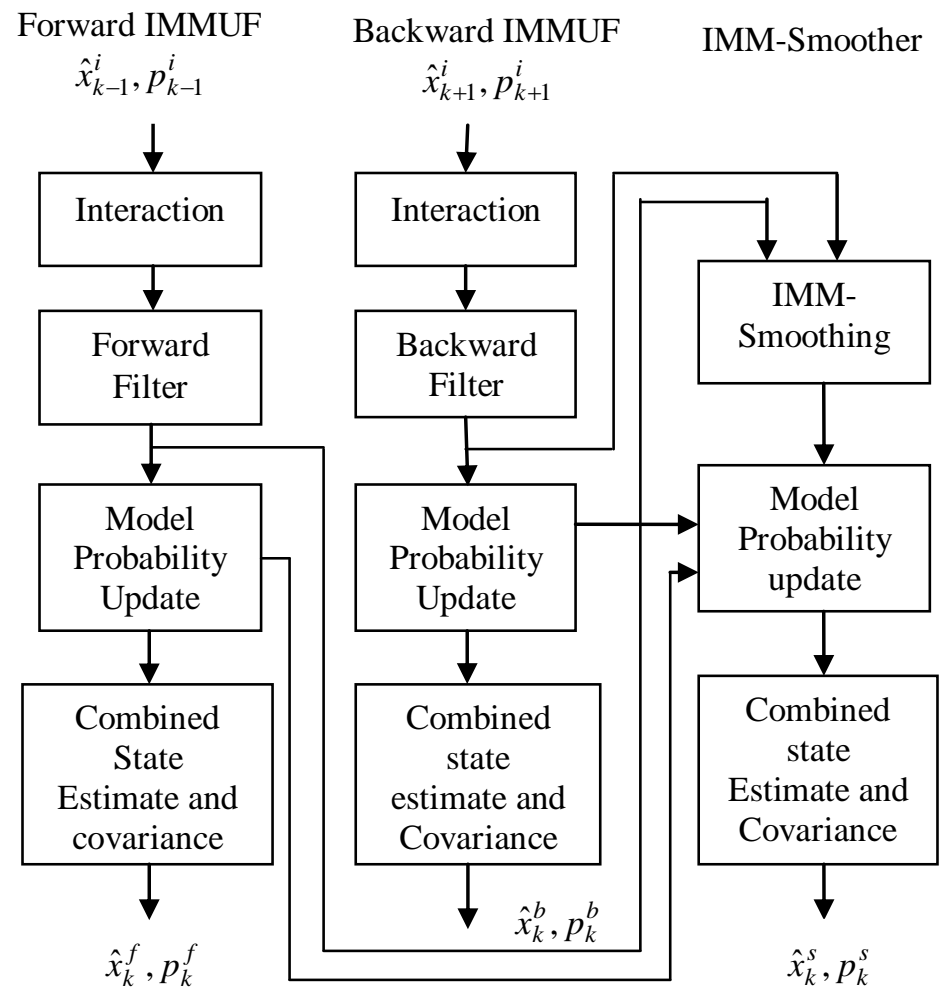

Figure 5. Detailed Block diagram of IMMUS algorithm

The integration of forward estimate and backward estimate using model probability is given in Fig.5.The estimate obtained in the forward IMM filter and back ward IMM filter and its corresponding covariances are used to obtain the smoothed estimate of vehicle's position.The Model conditioned estimate of forward and backward filters are combined by smoothing algorithm and is weighted by updated model probability to obtain the combined smoothed estimate.

\section{MODELING PARAMETERS FOR GPS NAVIGATION}

The aim is to estimate the state of the vehicle $\mathrm{x}_{\mathrm{k}}$ at the current time step $\mathrm{k}$ given a set of measurements (observations) $Z_{\mathrm{k}}=\left\{\mathrm{z}_{0}, \ldots \ldots . \mathrm{z}_{\mathrm{k}}\right\}$ acquired at time steps $0,1, \ldots ., \mathrm{k}$.The measurement noise is considered as white noise. It is assumed that the measurement noise has zero mean and the variance is set as $\sigma_{\mathrm{w}}^{2}=0.01$ 
To estimate the position of the moving vehicle using IMM-US, two kinematic models are introduced. They are Constant Velocity model (CV model) and Coordinated Turn model (CT model).

\section{A. Constant Velocity Model (CV):}

In this model, the vehicle is assumed to move with nearly constant velocity.The dynamic model for the constant velocity model is

$$
\mathrm{x}(\mathrm{k})=\mathrm{Fx}(\mathrm{k}-1)+\mathrm{Gv}(\mathrm{k}-1)
$$

where $\mathrm{F}$ is transition matrix and $\mathrm{G}$ is noise effect matrix and $\mathrm{v}(\mathrm{k})$ is process noise.

The state vector consists of position and velocity components.

$$
\begin{aligned}
& \mathrm{x}(\mathrm{k})=\left[\mathrm{x}_{\mathrm{e}}(\mathrm{k}) \mathrm{y}_{\mathrm{n}}(\mathrm{k}) \dot{\mathrm{x}}_{\mathrm{e}}(\mathrm{k}) \dot{\mathrm{y}}_{\mathrm{n}}(\mathrm{k})\right]^{\mathrm{T}}
\end{aligned}
$$

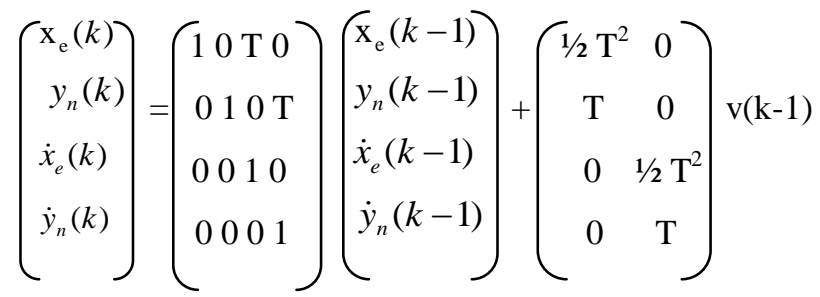

Measurement model is given by

$$
\mathrm{z}(\mathrm{k})=\mathrm{Hx}(\mathrm{k})+\mathrm{w}(\mathrm{k})
$$

The measurement vector has two elements

$$
\mathrm{z}(\mathrm{k})=\left[\mathrm{z}_{\mathrm{x}}(\mathrm{k}) \mathrm{z}_{\mathrm{y}}(\mathrm{k})\right]^{\mathrm{T}}
$$

where $\mathrm{H}$ is observation matrix and $\mathrm{w}(\mathrm{k})$ is the measurement noise. Since position along east $(\mathrm{x})$ and $\operatorname{north}(\mathrm{y})$ directions are considered, the observation matrix is taken as follow

B. Coordinated Turn Model (CT):

$$
\mathrm{H}=\left(\begin{array}{llll}
1 & 0 & 0 & 0 \\
0 & 1 & 0 & 0
\end{array}\right)
$$

A common way of modeling a turning vehicle is to use the coordinated turn model. In this model, a turn rate parameter $\Omega$ is included in the state vector.

The dynamic model for coordinated turn model is as follows

$$
\mathrm{x}(\mathrm{k})=\mathrm{Fx}(\mathrm{k}-1)+\mathrm{Gv}(\mathrm{k}-1)
$$

The state vector is taken as

$$
\mathrm{x}(\mathrm{k})=\left[\mathrm{x}_{\mathrm{e}}(k) y_{n}(k) \dot{x}_{e}(k) \dot{y}_{n}(k) \Omega(k)\right]^{T}
$$

$$
\left(\begin{array}{c}
\mathrm{x}_{\mathrm{e}}(k) \\
y_{n}(k) \\
\dot{x}_{e}(k) \\
\dot{y}_{n}(k) \\
\Omega(\mathrm{k})
\end{array}\right)=\left(\begin{array}{ccccc}
1 & 0 & \frac{\sin \Omega T}{\Omega} & -\frac{1-\cos \Omega T}{\Omega} & 0 \\
0 & 0 & \cos \Omega T & -\sin \Omega T & 0 \\
0 & 1 & \frac{1-\cos \Omega T}{\Omega} & \frac{\sin \Omega T}{\Omega} & 0 \\
0 & 0 & \sin \Omega T & \cos \Omega T & 0 \\
0 & 0 & 0 & 0 & 1
\end{array}\right)+\left(\begin{array}{c}
\mathrm{x}_{\mathrm{e}}(k-1) \\
y_{n}(k-1) \\
\dot{x}_{e}(k-1) \\
\dot{y}_{n}(k-1) \\
\Omega(k-1)
\end{array}\right)+\left(\begin{array}{cc}
1 / 2 \mathrm{~T}^{2} & 0 \\
\mathrm{~T} & 0 \\
0 & 1 / 2 \mathrm{~T}^{2} \\
0 & \mathrm{~T} \\
0 & 0
\end{array}\right) \mathrm{v}(\mathrm{k}-1)
$$

The observation matrix $\mathrm{H}$ is taken as follows

$$
\left.\mathrm{H}=1 \begin{array}{cccccc}
0 & 0 & 0 & 0 & 0 \\
0 & 1 & 0 & 0 & 0 & 0
\end{array}\right)
$$

The following transition probability matrices of the markov chain were used

$$
p_{i j}=\left[\begin{array}{ll}
0.9 & 0.1 \\
0.1 & 0.9
\end{array}\right]
$$

The prior model probability is set to

$$
\mu_{0}=\left[\begin{array}{ll}
0.95 & 0.05
\end{array}\right]
$$




\section{SIMULATION RESULTS}

The performance of IMMUS over the IMMUF in GPS navigation system is verified by creating a real trajectory as shown in figure. 6 and its associated randomly generated measurements. The simulation scenario is as follows. The vehicle motion is designed to cover a dynamic behaviors constant velocity and circular turn.

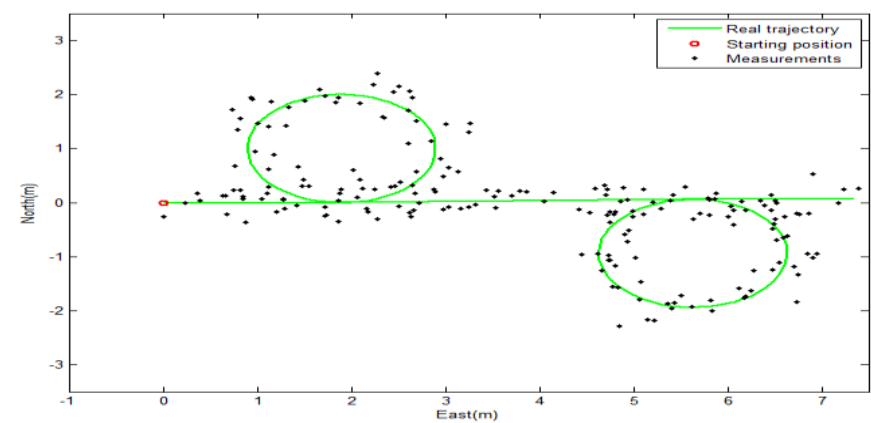

Figure .6.Two dimensional trajectory of simulated vehicle

The trajectory is simulated for 200 time steps with step size $\Delta t=0.1$. The movement of vehicle is as follows Vehicle starts from origin with velocity $(\dot{x}, \dot{y})=(1,0)$.

At $4 \mathrm{~s}$ vehicle starts to turn left with rate $\mathrm{w}=1$.

At $9 \mathrm{~s}$ vehicle stops turning and moves straight for 2 seconds with a constant total velocity of one.

At $11 \mathrm{~s}$ vehicle starts to turn right with rate $\mathrm{w}=-1$.

At 16s vehicle stops turning and moves straight for 4 seconds with the same velocity.

A sample of trajectory estimates for UKF,IMMUF and IMMUS are plotted in Fig.7. The average mean square errors of position estimates for 100 Monte Carlo runs are listed in Table.1. It can be observed that the estimates produced by IMMUS follows more closely with the real trajectory compared with single Modeled UKF and MMUF filter. The difference between IMMUS and individual IMMUF has grown in favor of proposed IMMUS.

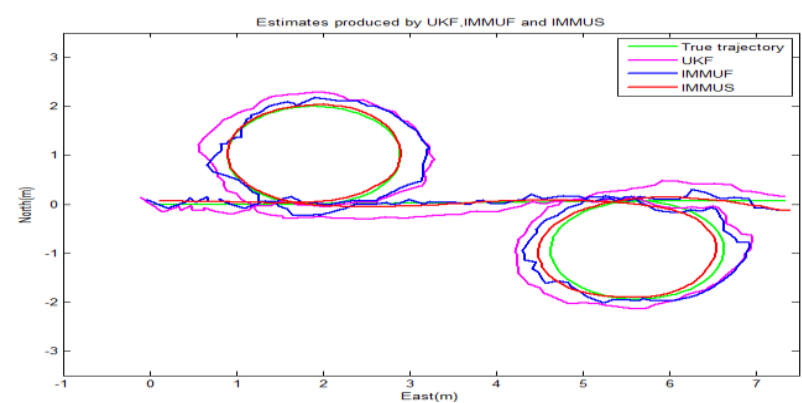

Figure .7 smoothed estimate of vehicle position

The Fig. 8 gives the variation of velocity model probability for both IMMUF and IMMUS. The Fig 9 gives the plot of turn model probability for IMMUF and IMMUS. Comparison of plot 8 and 9 , gives the idea about the changes in model probability between constant velocity model and coordinated turn model with respect to the actual vehicle dynamics.

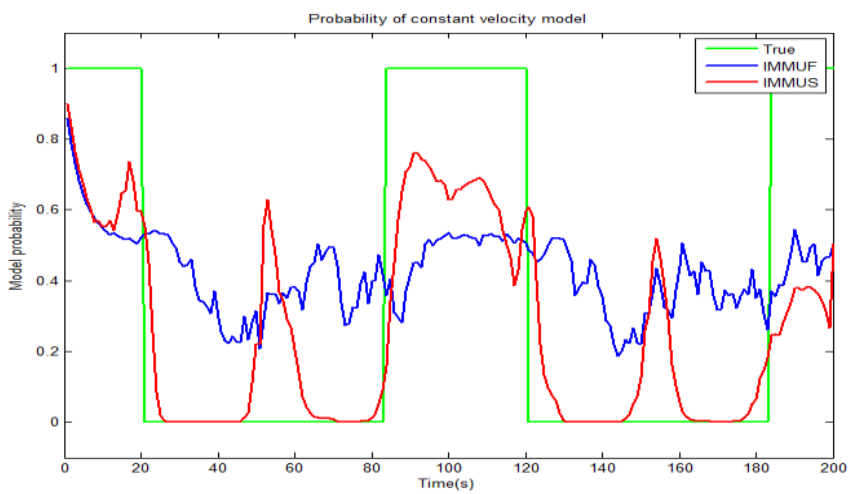

Figure .8.Constant velocity model probability 
The probability model weights more constant velocity model, when the vehicle is in non-maneuvering region and weights more turn model, when the vehicle is in maneuvering region. The figure 10 compares the vehicle position estimate of proposed IMMUS with that of IMMUF in east and north components.

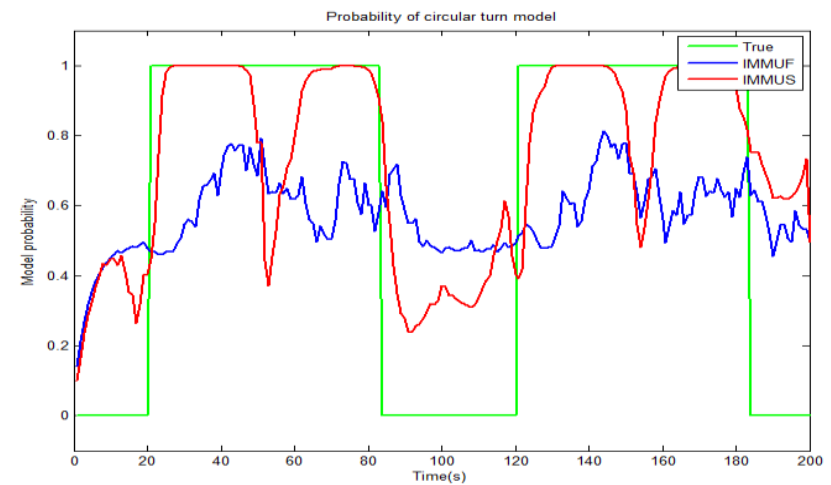

Figure 9.Co-ordinated turn model probability
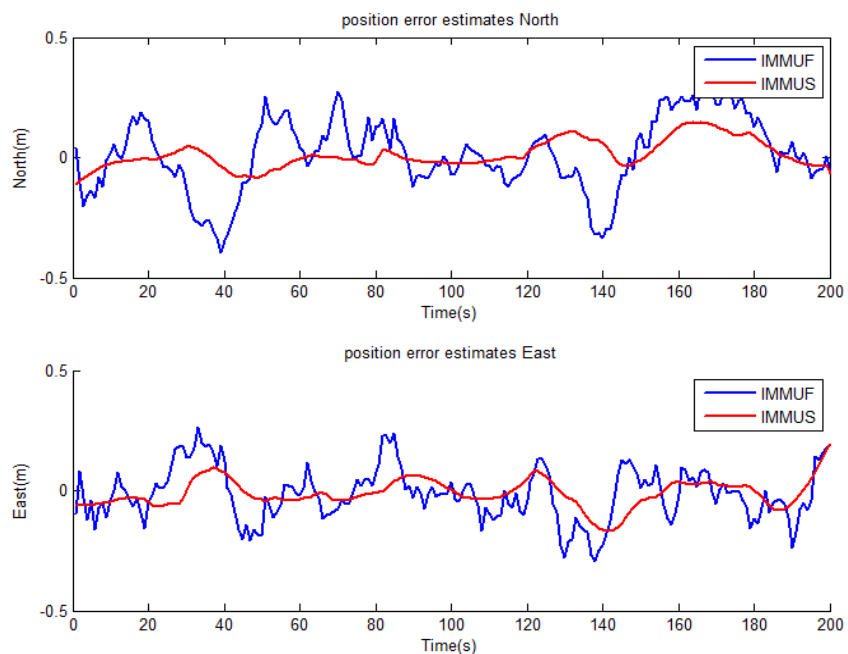

Figure 10 Vehicle position estimate in east and north components

The vehicle position estimate shows that IMMUS approach gives the accurate navigation estimate in the vehicle maneuvering and non-maneuvering region compared to the individual IMMUF.

Table .1 Average MSEs of estimating position of a simulated vehicle over 100 Monte Carlo Runs

\begin{tabular}{|c|c|c|}
\hline Methods & East & North \\
\hline UKF & 0.0847 & 0.1010 \\
\hline MMUF & 0.0124 & 0.0238 \\
\hline MMUS & 0.0035 & 0.0034 \\
\hline
\end{tabular}

In the table 1, the average MSEs of position estimates produced by the tested methods is listed. It can be seen that the estimates produced by proposed IMMUS using the combination of velocity and a coordinated turn model are clearly better than the ones produced by a IMMUF and single model UKF.

\section{CONCLUSION}

In this paper an IMMUS method is presented to improve the GPS navigation performance obtained by the IMMUF and conventional navigation filters. The GPS navigation accuracy based on the proposed method has been compared to the IMMUF and has demonstrated substantial improvement in both navigation accuracy and tracking capability. Future research can be conducted to improve the performance by incorporating artificial intelligence such as fuzzy logic and neural network. 


\section{References}

[1] Woei-Leong Chan and Fei-Bin Hsiao "Implementation of the Rauch -Tung-Striebel Smoother for sensor Compatibility correction of a Fixed-Wing Unmanned Air vehicle", Sensor Publications, 11,3738-3764,2011.

[2] Helmick,R.E.,Blair,W.D., and Hoffman "Fixed-interval smoothing for Markovian switching systems",IEEE Trans.Information Theory, Vol.41,No.6,pp.1845-1855.Nov.1995.

[3] Jilkov,V.P.,Li,X.R., "Performanence enhancement of the IMM estimation by smoothing",in Proc.Int.Conf.Information Fusion,vol.1,pp.713-720,2002.

[4] Chen,B., and Tugnait,J.K., "Interacting multiple model fixed -lag smoothing algorithm for markovian switching systems",IEEE Trans.Aerospace and Electronic systems, Vol.36,No.1,pp.432-500,jan2002.

[5] Modelling and parameter Estimation of Dynamic Systems by J.R.Raol,G.Girija and J.Singh.

[6] A solution manual and Notes for:Applied Optimal Estimation by Arthur Gelp

[7] Ali Almagbile, Jinling Wang, "Evaluating the performances of Adaptive Kalman Filter Methods in GPS /INS Integration", journal of global positioning systems, 9, 33-40, 2010

[8] Chien-hao tseng and Dae-Jung jwo "GPS navigation processing using the IMM based Extended kalman filter for integrated navigation sensor fusion", Sensor Publications, 6, 4-17, 2009.

[9] Fong-Chi Chung "Fuzzy adaptive Unscented Kalman Filter for Ultra-Tight GPS/INS Integration", International Symposium on computational Intelligence and Design, 2010.

[10] YanLIng Hao and Zhen Guo "Adaptive Extended Kalman Filtering for INS/GPS integrated navigation systems", International joint conference on Computational Sciences and Optimization, 2009.

[11] Honghui Qi et.al, "Direct Kalman Filtering approach for GPS/INS Integration"IEEE Transaction on Aerospace and Electronic systems, 37,687-693, 2002. 